\title{
DEVELOPMENT AND VALIDATION OF AN ANALYTICAL METHOD FOR THE DETERMINATION OF METHYLISOTHIAZOLINONE AND METHYLCHLOROISOTHIAZOLINONE IN COSMETIC PRODUCTS USING MATRIX SOLID-PHASE DISPERSION COUPLED TO GAS CHROMATOGRAPHY-MASS SPECTROMETRY
}

\author{
NURINA PRAPURANDINA*, HARMITA HARMITA, HERMAN SURYADI
}

Faculty of Pharmacy, Universitas Indonesia, Depok, West Java, Indonesia

Email: nurina.prapurandina@gmail.com

Received: 20 Oct 2020, Revised and Accepted: 22 Dec 2020

\begin{abstract}
Objective: This study was to develop the first simultaneous method for quantification of MI and MCI by using matrix solid-phase dispersion (MSPD) as an extraction technique followed by gas chromatography-tandem mass spectrometry (GC-MS) in cosmetic products to support that law enforcement.

Methods: The MI and MCI were extracted from the cosmetic sample by using matrix solid-phase dispersion technique with alumina as solid sorbent and ethyl acetate as eluent. After being isolated, MI and MCI from the samples were analyzed using GC-MS equipped with DB-5MS capillary column.

Results: The validated method for both leave-on and rinse-off cosmetic showed that MI and MCI recoveries were between $97.87-103.15 \%$, relative standard deviation (RSD) values were lower than 11\%, and limit of quantitation (LOQ) values for the leave-on product were $0.96 \mu \mathrm{g} / \mathrm{ml}$ and 1.95 $\mu \mathrm{g} / \mathrm{ml}$ and for rinse-off products were $0.56 \mu \mathrm{g} / \mathrm{ml}$ and $1.49 \mu \mathrm{g} / \mathrm{ml}$ for MI and MCI, respectively.
\end{abstract}

Conclusion: This purposed analytical method for determining MI and MCI in cosmetic products using MSPD-GC-MS complies with the validation acceptance criteria.

Keywords: Methylisothiazolinone, Methylchloroisothiazolinone, Matrix solid-phase dispersion, Gas chromatography-mass spectrometry, Validation

(C) 2021 The Authors. Published by Innovare Academic Sciences Pvt Ltd. This is an open access article under the CC BY license (https://creativecommons.org/licenses/by/4.0/) DOI: https://dx.doi.org/10.22159/ijap.2021v13i2.40058. Journal homepage: https://innovareacademics.in/journals/index.php/ijap

\section{INTRODUCTION}

Most cosmetic products, especially the ones with high water contents, are easily contaminated by microorganisms, so the manufacturers add preservatives to their products to prevent the product degradation. Isothiazolinone preservative group, particularly methylisothiazolinone (MI) and methylchloroisothiazolinone (MCI), is widely used in cosmetic products formulation for both rinse-off products (shampoo and conditioner) and leave-on products (cream, sunscreen, wet tissues), because this type of preservative manifests a great broadspectrum antimicrobial activity at low concentration. MI can be used alone or in combination with $\mathrm{MCI}$ as a 3:1 MCI/MI mixture which is commercially sold under the name of Kathon CG (cosmetic grade) [1].

Despite the benefits that have been offered by these preservatives, MCI and MI in cosmetic products have been known to cause allergic contact dermatitis because these chemicals are moderate to strong sensitizers. The increase in the prevalence of contact allergy caused by MCI/MI and MI alone was reported in several European countries between 2009 and 2015, especially case that involved MI alone. The prevalence decreased after European Commission amended the regulations regarding the use of these preservatives. MCI/MI has been prohibited to be present in leave-on products but still can be used in rinse-off products from 2016. Moreover, in 2017, the maximum limit concentration of MI in rinse-off products was reduced from $0.01 \%$ to $0.0015 \%$ and should not also be present in leave-on products [2]. Consequently, in 2019, the Indonesian Food and Drug Authority (Indonesian FDA) also amended the regulation, which stated that the use of both of MI alone and MCI/MI in rinse-off products has been authorized at levels not exceeding $0.0015 \%$ and prohibited in leave-on products [3].

To guarantee product safety and ensure compliance with existing government regulations, it is necessary to have a reliable and valid analytical method for the identification and determination of the actual levels of MI and MCI in cosmetics. This is also important in meeting consumers' expectations. as awareness of tainted cosmetics and skin infection increases [4-6]. Maximum concentration restriction and prohibition of these preservatives used in cosmetic products formula combined with the complexity of cosmetic matrices may represent a challenge for developing an effective and valid analytical method. Most analytical methods that had been previously developed to analyze MI and MCI in various matrices involved the use of HPLCUV, HPLC-DAD, LC-MS, LC-MS/MS, and GC-MS which UHPLC MS/MS provided good results in the determination of isothiazolinones in different matrices [7]. This study employed GC-MS, instead of UPLC MS/MS, in order to discover an alternative analytical method to UHPLC MS/MS for analyzing MI and MCI in cosmetic matrices.

The use of GC-MS does not show, in general, good performance for MI and MCI analysis in wastewater. This method employed liquid-liquid extraction (LLE) or solid-phase extraction (SPE) as the extraction procedures. However, poor MI extraction yields have been obtained from high water-content matrices due to the high polarity and water solubility of MI [8]. To elevate the extraction efficiency and GC-MS performance, matrix solid-phase dispersion (MSPD) was proven as a valuable choice. MSPD is a simplified version of SPE in which reducing sample dissolving step and a proficient extraction method for solid, semi-solid, and sticky samples [9]. MSPD followed by HPLC-MS/MS had been proven to be an effective extraction technique to isolate MI and MCI in cosmetic matrices [10]. Moreover, another study also showed that the performance of MSPD followed by GC-MS was better than SPE or LLE techniques to extract MI and MCI in liquid air freshener samples [11].

The aim of this study is the development of a valid and reliable method for the determination of MI and MCI in a broad spectrum of cosmetic samples, including both rinse-off and leave-on products, employing MSPD followed by GC-MS. To the best of our knowledge, this is the first time that MSPD-GC-MS is applied to the analysis of isothiazolinones in cosmetic matrices.

\section{MATERIALS AND METHODS}

\section{Chemical and reagents}

A mixture of MI and MCI (1:3) was acquired as ProClin ${ }^{\mathrm{TM}}$ reference standard (1.485\% in water: $0.37 \%$ MI, $1.115 \%$ MCI) from Sigma Aldrich (Saint Louis, Missouri, USA). 1-Chlorodecan (98\% purity) 
used as internal standards was purchased from Sigma-Aldrich. Analytical grade reagents such as acetone, ethyl acetate, n-hexane, acetic acid glacial, ethanol, and methanol were purchased from Merck (Darmstadt, Germany).

For the MSPD extraction procedure sorbents, neutral alumina, and sand (50-70 mesh) were purchased from Sigma Aldrich (Saint Louis, Missouri, USA) and florisil (60-100 mesh) was purchased from Merck (Darmstadt, Germany). Alternative sorbents were alumina from PT. Indonesia Chemical Alumina (Sanggau, West Borneo, Indonesia) which in this paper would be referred to as local alumina and local quartz sand obtained from CV. Pasir Mas (Rembang, Central Java, Indonesia) which would be referred to as local quartz sand. Before being used, florisil, alumina, local alumina, and sand were activated at $130{ }^{\circ} \mathrm{C}$ for $12 \mathrm{~h}$ and then allowed to cool down. Local quartz sand (about $0.5 \mathrm{~kg}$ ) was washed 3 times with distilled water (approximately $1.5 \mathrm{~L}$ ) and 3 times with ethanol 96\% (approximately $1.5 \mathrm{~L}$ ), and dried for $24 \mathrm{~h}$ in an oven at $100^{\circ} \mathrm{C}$ [12]. Sodium sulphate anhydrous (99\%) was purchased from Merck.

\section{Samples}

A wide variety of cosmetics were purchased from local markets and drugstores. For rinse-off cosmetics, three different shampoos, three different conditioners, three rinse-off products that are intended for children and babies, two liquid soaps, and a face cleanser were used. Representing leave-on cosmetics, a face cream, sunscreen, a body lotion, and three wet wipes were used. All of these products were labeled as containing either combination MCI/MI or MI alone. Different samples used for method optimization and validation were shampoo representing the rinse-off product and sunscreen cream for the leave-on product. Both of them are labeled as isothiazolinone-free products.

\section{Instruments}

The gas chromatographic analysis was performed using an Agilent (Santa Clara, California, USA) 7890A gas chromatograph equipped with split/splitless injector coupled to an Agilent mass spectrometer MSD 5975C. The source was electron ionization (EI) with an energy of $70 \mathrm{eV}$. Helium $(99.999 \%$ purity) was used as carrier gas. The separation was performed using an Agilent J and W DB-5MS (30m, $0.25 \mathrm{~mm}, 0.25 \mu \mathrm{m}$ ) capillary column. The data acquisition and processing were carried out by the GC/MSD Chem Station Software.

MSPD extraction was conducted in commercially available $20 \mathrm{ml}$ Bond Elute Empty SPE Cartridge with $20 \mu \mathrm{m}$ polypropylene frits from Agilent technologies. Vac Elut 20 position was used to help the elution process from Agilent technologies. For vortex-assisted MSPD (VA-MSPD), a Hettich zentrifugen 320R from Andreas Hettich GmbH and Co. KG (Tuttlingen, Germany) centrifuge and LP vortex-mixer 88880018 from Thermo Fisher Scientific (Massachusetts, USA) were used as additional instruments.

\section{Chromatographic system}

The GC-MS injector temperature was set constantly at $250{ }^{\circ} \mathrm{C}$ and the injection volume was $2 \mu \mathrm{l}$ (splitless). The condition selected for programming the oven temperature was: $60^{\circ} \mathrm{C}$ for $2 \mathrm{~min} ; 2{ }^{\circ} \mathrm{C} / \mathrm{min}$ to $175^{\circ} \mathrm{C}$ for $7 \mathrm{~min} ; 50^{\circ} \mathrm{C} / \mathrm{min}$ to $295^{\circ} \mathrm{C}$ for $10 \mathrm{~min}$, and helium gas flow of $1.2 \mathrm{ml} / \mathrm{min}$. The transfer line was also set at $280{ }^{\circ} \mathrm{C}$, quadrupole temperature at $150{ }^{\circ} \mathrm{C}$, and source temperature at 230 ${ }^{\circ} \mathrm{C}$. For optimization purposes, full-scan spectra from $\mathrm{m} / \mathrm{z} 50$ to $\mathrm{m} / \mathrm{z}$ 400 were used. After optimum condition was reached, to obtain maximum sensitivity, the quadrupole mass spectrometer was run in SIM (selected ion monitoring) mode. Selected SIM fragment masses for quantification and identification are given in table 1.

Table 1: Fragment masses for determination of isothiazolinone in SIM mode

\begin{tabular}{ll}
\hline Compound & Fragment masses m/z \\
\hline MI & $115,87,58$ \\
MCI & $149,57,85$ \\
1-Chlorodecane & $43,91,57$ \\
\hline
\end{tabular}

\section{Preparation of standard solutions}

For GC-MS analysis, ProClin ${ }^{\mathrm{TM}}$ reference standard was accurately weighed and dissolved with ethyl acetate to produce $37.4 \mu \mathrm{g} / \mathrm{ml}$ and $112.6 \mu \mathrm{g} / \mathrm{ml}$ of MI and MCI, respectively. A standard stock solution was accurately taken and diluted with ethyl acetate to produce calibration curve solution. 1-Chlorodecane as internal standard was prepared by accurately weighing and dissolved in ethyl acetate to produce $300 \mu \mathrm{g} / \mathrm{ml}$.

\section{Preparation of cosmetic sample solution}

$0.5 \mathrm{~g}$ of cosmetic sample were exactly weighted into glass mortar. The sample was gently blended with $1.0 \mathrm{~g}$ of a drying agent (anhydrous $\mathrm{Na}_{2} \mathrm{SO}_{4}$ ) and $2.0 \mathrm{~g}$ of dispersing sorbent in glass mortar using a glass pestle until a homogenous mixture was obtained. Then the mixture was transferred into an empty solid-phase extraction (SPE) cartridge with polypropylene frit at the bottom. A second frit was placed on the top of the sample before compression with a syringe plunger. Elution was made with the help of a vacuum pump by using $5.0 \mathrm{ml}$ of ethyl acetate, then the eluate was collected into a conical tube and analyzed with GC-MS.

In vortex-assisted (VA) MSPD, $1.0 \mathrm{~g}$ solid support and $2.0 \mathrm{~g}$ of $\mathrm{Na}_{2} \mathrm{SO}_{4}$ were added and the mixture was macerated using a pestle for approximately $5 \mathrm{~min}$, following which the mixture was transferred to a centrifuge tube. Next, $5.0 \mathrm{ml}$ ethyl acetate was added, and the tube was agitated in a vortex for $30 \mathrm{sec}$ and followed by centrifugation for $15 \mathrm{~min}$ at $4000 \mathrm{rpm}$. An aliquot of the extract was then collected for analysis by GC-MS.

\section{Method validation and matrix effect}

The method was validated according to ICH guidelines and its specificity, linearity, matrix effect, accuracy, repeatability (intra-day precision), intermediate precision (inter-day precision), limit of detection (LOD), and limit of quantification (LOQ) was evaluated [13]. Specificity of the method was demonstrated by the separation of MI, MCI, and internal standard of 1-chlorodecane without any interference peaks from matrix samples. Calibration standard curve was constructed in the solvent (ethyl acetate) and plotted over 1.87$22.5 \mu \mathrm{g} / \mathrm{ml}$ for MI and $5.64-67.5 \mu \mathrm{g} / \mathrm{ml}$ for MCI.

Linearity curve was prepared in the blank matrix extract over concentration range at $2.25-6.75 \mu \mathrm{g} / \mathrm{ml}$ for $\mathrm{MI}$ and $5.25-15.25$ $\mu \mathrm{g} / \mathrm{ml}$ for MCI. Method accuracy was assessed using a recovery study at 3 different concentrations by spiking blank samples. The method precision was expressed as relative standard deviation (RSD) and evaluated for repeatability and intermediate precision. LOD and LOQ were calculated using the regression equation approach applying the following formula [14].

$$
\begin{aligned}
\text { Sy } / x & =\sqrt{\frac{\sum(y-y 1)^{2}}{n-2}} \\
\text { LOD } & =\frac{3 \cdot S y / x}{b} \\
L O Q & =\frac{10 \cdot S y / x}{b}
\end{aligned}
$$

Where Sy/ $\mathrm{x}$ is the residual standard deviation of the linear regression and $\mathrm{b}$ is the slope

The matrix effect was quantified by comparing the signal of a pure standard solution of the target analyte with the signal obtained with a standard solution at the same concentration prepared in the extract of shampoo and sunscreen matrix. Shampoo represented the rinse-off cosmetic and sunscreen was selected as an example of the leave-on cosmetic. Matrix effect (ME) was estimated by comparing 
the peak area of the analytes recorded for the standard solution (A) with peak area of the analytes recorded for the blank sample spiked with the target compounds after extraction (B). The matrix effect was calculated as:

$$
\operatorname{ME}(\%)=\left(\frac{B}{A}-1\right) \times 100 \% \text {..[15]. }
$$

\section{Analysis of market samples}

GC-MS methods were performed to determine the MI and MCI concentration in 18 cosmetic samples obtained from the market.

\section{Statistical analysis}

Data were processed with IBM SPSS statistical software versions 26.

\section{RESULTS AND DISCUSSION}

\section{Solvent optimization}

ProClin $^{\text {TM }}$ reference standard $(14850 \mu \mathrm{g} / \mathrm{ml})$ was used as a stock solution of MI $(3700 \mu \mathrm{g} / \mathrm{ml})$ and MCI $(11150 \mu \mathrm{g} / \mathrm{ml})$. The use of
ProClin ${ }^{\mathrm{TM}}$ as standard for those two analytes was justified by the widespread use of this mixture as the common form isothiazolinones that present in cosmetic formulations. Designated solvents to dilute this mixture were investigated in this study in order to obtain the most proper solvent that could elute both MI and MCI. Fig. 1 shows the chromatogram corresponding to a standard solution of $150 \mu \mathrm{g} / \mathrm{ml}$ of ProClin $^{\text {TM }}$ (MI: $37.4 \mu \mathrm{g} / \mathrm{ml}$, MCI: 112.6 $\mu \mathrm{g} / \mathrm{ml})$. As can be seen, a much better peak shape was obtained using ethyl acetate as solvent and MI could only be detected in this condition.

This result was different from the previous study conducted by Park and Kwon, which stated that the solvent used was methanol for the standard stock solution of MI and MCI, and acetone as final solvent before analyzing by GC-MS. This is probably due to differences in the selection of the MI and MCI standard used. These authors used MI and MCI as individual standards. Meanwhile, this study used ProClin ${ }^{\mathrm{TM}}$ reference standard, which is a mixture of MI and MCI (1:3) because the mixture is used widely in cosmetic formulations and contains not only $\mathrm{MI}$ and MCI but also magnesium nitrate and water [11].

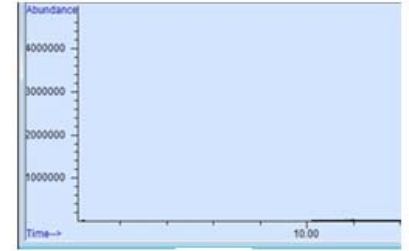

(a)

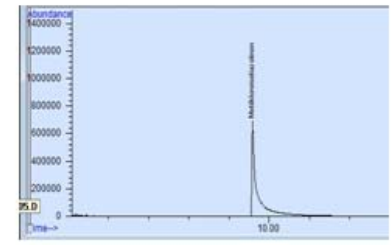

(d)

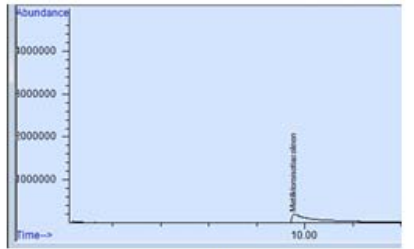

(b)

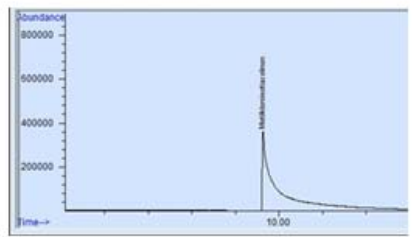

(e)

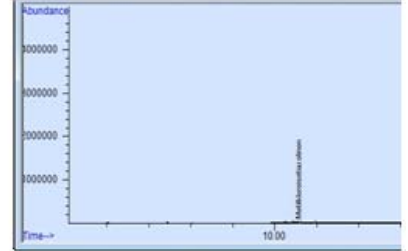

(c)

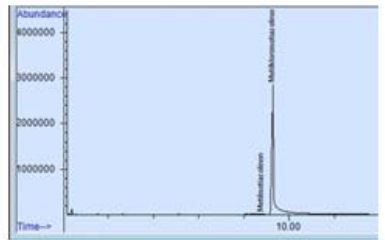

(f)

Fig. 1: Chromatograms for standard solutions containing the $\mathrm{MI}$ at concentratiom $37.5 \mu \mathrm{g} / \mathrm{ml}$ and $\mathrm{MCI}$ at concentration of $112.5 \mu \mathrm{g} / \mathrm{ml}$ : (a) in acetone (b) in acetonitrile (c) methanol (d) n-hexane (e) n-hexane: acetone (1:1 v/v) (f) ethyl acetate

\section{Chromatographic system optimization}

The parameters optimized in the chromatographic system were: initial column oven temperature, injector temperature, and temperature programming. A two-level factorial design was performed: the initial column oven temperature was $50^{\circ} \mathrm{C}$ and $60^{\circ} \mathrm{C}$, injector temperature was $250{ }^{\circ} \mathrm{C}$ and $270{ }^{\circ} \mathrm{C}$ and then programmed using two different temperature programming for each analysis: (1) $50 / 60{ }^{\circ} \mathrm{C}$ for $2 \mathrm{~min}, 10^{\circ} \mathrm{C} / \mathrm{min}$ to $50^{\circ} \mathrm{C}$ for $4 \mathrm{~min}, 20^{\circ} \mathrm{C} / \mathrm{min}$ to $280^{\circ} \mathrm{C}$ for $2 \mathrm{~min}$ and (2) $50 / 60{ }^{\circ} \mathrm{C}$ for $2 \mathrm{~min}, 25^{\circ} \mathrm{C} / \mathrm{min}$ to $175^{\circ} \mathrm{C}$ for $7 \mathrm{~min}$, $50{ }^{\circ} \mathrm{C} / \mathrm{min}$ to $295{ }^{\circ} \mathrm{C}$ for $10 \mathrm{~min}$. The results for chromatography optimization are shown in table 2.
Given these results, temperature programming has an impact on defining peak area, especially for MCI, which is described by independent $t$-test result. The $p$-value tests the statistical significance of each factor and the relevance of the temperature programming in the chromatographic analysis is evidenced $\left({ }^{*} \mathrm{p}\right.$ value $<0.05$ ) for MCI (table 3). Hence, the selected experimental conditions for chromatographic conditions that could give optimal area for both MI and MCI comprise initial column oven temperature at $60{ }^{\circ} \mathrm{C}$, injector temperature at $250^{\circ} \mathrm{C}$ and temperature programming at $60^{\circ} \mathrm{C}$ for $2 \mathrm{~min}, 25^{\circ} \mathrm{C} / \mathrm{min}$ to $175^{\circ} \mathrm{C}$ for $7 \mathrm{~min}, 50^{\circ} \mathrm{C} / \mathrm{min}$ to $295^{\circ} \mathrm{C}$ for $10 \mathrm{~min}$.

Table 2: Influence of initial column oven temperature, injector temperature, and temperature programming on MSD response

\begin{tabular}{|c|c|c|c|c|c|}
\hline \multirow[t]{2}{*}{ Flow rate } & \multirow{2}{*}{$\begin{array}{l}\text { Initial column oven } \\
\text { temperature }\left({ }^{\circ} \mathrm{C}\right)\end{array}$} & \multirow{2}{*}{$\begin{array}{l}\text { Injector } \\
\text { temperature }\left({ }^{\circ} \mathrm{C}\right)\end{array}$} & \multirow{2}{*}{$\begin{array}{l}\text { Temperature } \\
\text { programming }\end{array}$} & \multicolumn{2}{|l|}{ Peak area } \\
\hline & & & & MI & MCI \\
\hline \multirow[t]{8}{*}{$1.2 \mathrm{ml} / \mathrm{min}$} & 50 & 250 & 1 & $\mathbf{0}$ & 81487600 \\
\hline & 50 & 250 & 2 & 624689 & 110067000 \\
\hline & 50 & 270 & 1 & 846395 & 65713000 \\
\hline & 50 & 270 & 2 & 379339 & 113573000 \\
\hline & 60 & 250 & 1 & 0 & 52760000 \\
\hline & 60 & 250 & 2 & 3988890 & 110551000 \\
\hline & 60 & 270 & 1 & 852716 & 67891500 \\
\hline & 60 & 270 & 2 & 3630550 & 109746000 \\
\hline
\end{tabular}

Temperature programming 1 : initial column oven held for $2 \mathrm{~min}, 10^{\circ} \mathrm{C} / \min$ to $50^{\circ} \mathrm{C}$ held for $4 \min , 20^{\circ} \mathrm{C} / \min$ to $280^{\circ} \mathrm{C}$ for 2 min, Temperature programming 2: initial column oven held for $2 \mathrm{~min}, 25^{\circ} \mathrm{C} / \mathrm{min}$ to $175^{\circ} \mathrm{C}$ held for $7 \mathrm{~min}, 50^{\circ} \mathrm{C} / \mathrm{min}$ to $295^{\circ} \mathrm{C}$ for $10 \mathrm{~min}$ 
Table 3: The results of independent t-test to show significance of main effect

\begin{tabular}{lllllll}
\hline No & Parameter & MI & & & MCI \\
\cline { 3 - 6 } & & F value & F table & p & F value & F table \\
\hline 1 & Initial column oven & 0.157 & 2.447 & 0.880 & 0.716 & 2.447 \\
2 & Injector temperature & 1.416 & 2.447 & 0.206 & 0.000 & 2.447 \\
3 & Temperature & 0.457 & 2.447 & 0.664 & 5.885 & 2.447 \\
& programming & & & & \\
\end{tabular}

\section{MSPD extraction optimization}

Although MSPD selectivity depends on both the nature of the sorbent materials and the elution solvent employed, according to the result of solvent optimization, MI and MCI could only be detected with ethyl acetate as the eluent. Therefore, this study was performed to evaluate the dispersive phase effect on the MSPD procedure. Extraction of MI and MCI from the leave-on product (sunscreen) and rinse-off product (shampoo) were evaluated using five sorbents, including florisil, alumina, sand, local alumina, and local quartz sand. For sample preparation, MSPD performed as usual MSPD procedure and 1 modification in MSPD procedure, VA-MSPD with the use of vortex. Thus, a multifactor categorical $2 \times 5$ design involving 10 randomized experiments was proposed.

The most usual solid sample/sorbent material ratio was used to accomplish MSPD, blending $2.0 \mathrm{~g}$ of sorbent material with $0.5 \mathrm{~g}$ of sample. Due to the high water solubility of MI and MCI, drying of the sample was essential. Hence, $1.0 \mathrm{~g}$ of anhydrous sodium sulphate was added in all MSPD experiments. After eluting the columns, $5 \mathrm{ml}$ of eluate were collected. The results of MSPD extraction optimization were shown in table 4 and fig. 2. Extraction efficiencies are investigated by observing the response ratio of both analytes to internal standard 1-chlorodecane and remarked the ratio of MCI/MI because the concentration ratio of $\mathrm{MCI}$ and MI was supposed to be 3 .

Fig. 2 shows the sorbent-extraction technique plots for the target isothiazolinone. In general, higher extraction efficiency was attained using alumina as sorbent, especially for MCI. Meanwhile, sand as sorbent combined with the VA-MSPD extraction technique could extract MI effectively. VA-MSPD showed generally better performance than MSPD with all sorbent, except for alumina. Application of vortex agitation as an extra source of energy to the extraction column is proved to contribute to the improvement of the extraction efficiency. Therefore, this technique requires further optimization, including vortex agitation time, centrifuge rotor speed, and centrifuge time to elevate its potency to become an alternative for the MSPD technique.

Regarding the use of local Indonesia sorbents, such as local alumina and local quartz sand, the value of extraction efficiencies was comparable with the sand obtained from Sigma-Aldrich for both analytes especially when the MSPD technique was used. This result indicates that quartz sand from Rembang as Indonesia's local sorbent has a prominent prospect to become solid support for extraction techniques that need abrasive sorbent, like MSPD. On the other hand, local alumina's performance was below the other sorbents because Indonesian alumina is produced with no intention to have abrasive properties.

According to these results, alumina was chosen as selected sorbent and MSPD for the extraction technique. This combination could isolate both $\mathrm{MI}$ and MCI more effectively than the other options and gave the ratio of $\mathrm{MCI} / \mathrm{MI}$ close to the value of 3.0, which was the same value of ratio MCI/MI in ProClin ${ }^{\mathrm{TM}}$ reference standard. MSPD with alumina as solid support was also the selected combination for extraction MI and MCI in liquid air freshener matrix in the previous study [11].

Table 4: Influence of extraction technique and sorbent on GC-MS Response

\begin{tabular}{|c|c|c|c|c|c|c|c|}
\hline \multirow{2}{*}{$\begin{array}{l}\text { Extraction } \\
\text { technique }\end{array}$} & \multirow[t]{2}{*}{ Sorbent } & \multicolumn{3}{|l|}{ Area } & \multicolumn{2}{|c|}{ Peak area ratio (PAR) } & \multirow[t]{2}{*}{ MCI/MI } \\
\hline & & MI & MCI & 1-Chlorodecane & MI & MCI & \\
\hline MSPD & Florisil & 290181 & 864424 & 434154 & 0.668 & 1.991 & 2.980 \\
\hline MSPD & Alumina & 270313 & 766432 & 340404 & 0.794 & 2.252 & 2.836 \\
\hline MSPD & Sand & 165999 & 444002 & 270377 & 0.614 & 1.642 & 2.674 \\
\hline MSPD & Local Alumina & 63258 & 148391 & 131839 & 0.480 & 1.126 & 2.346 \\
\hline MSPD & Local Quartz Sand & 202271 & 511756 & 314421 & 0.643 & 1.628 & 2.532 \\
\hline VA-MSPD & Florisil & 218655 & 429821 & 208980 & 1.046 & 2.057 & 1.966 \\
\hline VA-MSPD & Alumina & 183281 & 572043 & 298566 & 0.614 & 1.916 & 3.120 \\
\hline VA-MSPD & Sand & 519817 & 491955 & 278908 & 1.863 & 1.764 & 0.947 \\
\hline VA-MSPD & Local Alumina & 211909 & 541551 & 330850 & 0.640 & 1.637 & 2.558 \\
\hline VA-MSPD & Local Quartz Sand & 201735 & 502890 & 269943 & 0.747 & 1.863 & 2.494 \\
\hline
\end{tabular}
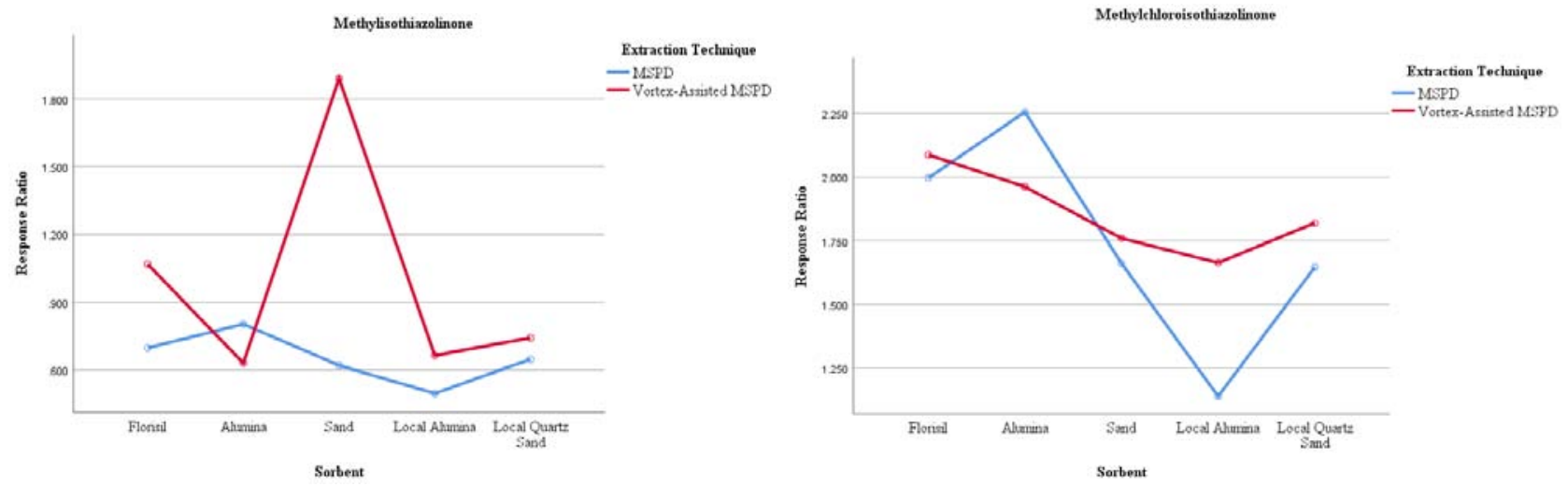

Fig. 2: Interaction plots for MI and MCI 


\section{Method validation}

\section{Specificity}

The results of $2 \mu$ injections of six solutions consisted of ethyl acetate; mixture standards of MI, MCI, and 1-chlorodecane; leave-on and rinse-off blank matrix samples; and leave-on and rinse-off spiked samples were analyzed under the selected optimum conditions. The presence of matrix interferences was examined by monitoring the selected ion monitoring
(SIM) mode chromatogram for each analyte at the retention time window expected for each compound. Although there were co-extracted compounds from both leave-on and rinse-off matrices during extraction, the mass spectra profiles for each compound were distinctive compared to the standard's mass spectra profile which proves that the analytical method was capable to assess unequivocally the MI and MCI in the presence of another component in matrix samples. The chromatograms of specificity can be seen in fig. 3 until fig. 8 .

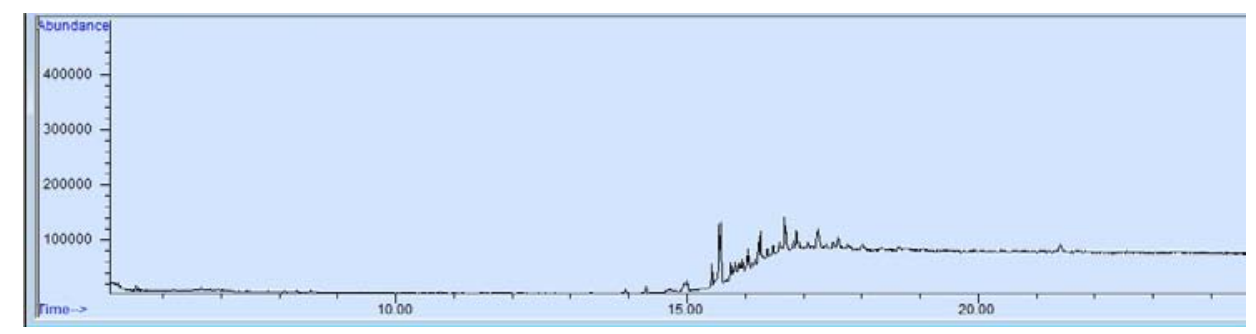

Fig. 3: Chromatogram of ethyl acetate

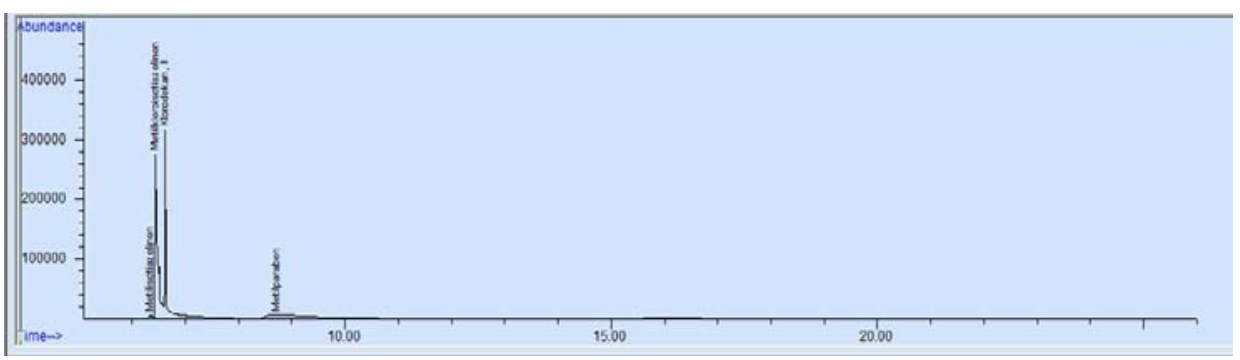

Fig. 4: Chromatogram of MI, MCI, and 1-Chlorodecane standard solution

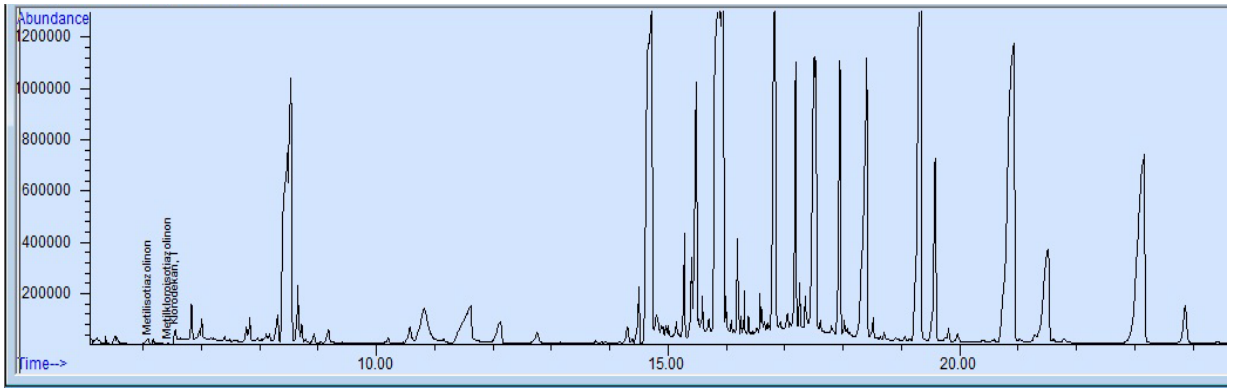

Fig. 5: Chromatogram of leave-on blank matrix sample

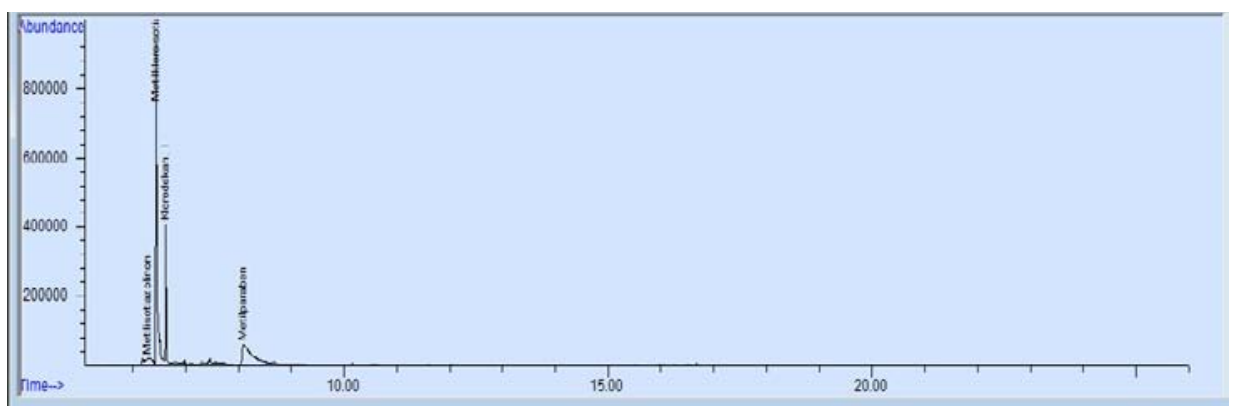

Fig. 6: Chromatogram of the leave-on spiked sample

\section{Linearity}

Linearity was studied employing calibration curves in the 7.5-90 $\mu \mathrm{g} / \mathrm{ml}$ in extraction solvent (solvent calibration/SC) and the 9-21 $\mu \mathrm{g} / \mathrm{ml}$ in matrix-matched of leave-on and rinse-off samples (matrix
calibration/MC). Linearity meets the acceptance criteria if the correlation coefficient $(\mathrm{r}) \geq 0.995$ and $\mathrm{VxO}$ is $\leq 5.0 \%$. $\mathrm{R}$ and $\mathrm{Vxo}$ values from MI and MCI in solvent calibration curves and matrix calibration curves are shown in table 5 . As can be seen, all of the $r$ and Vxo values met the criteria of acceptance. 


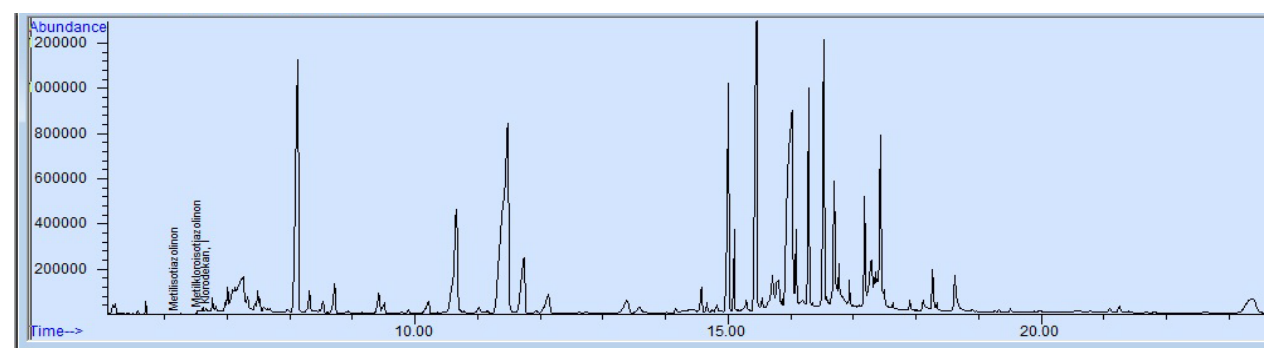

Fig. 7: Chromatogram of rinse-off blank matrix sample

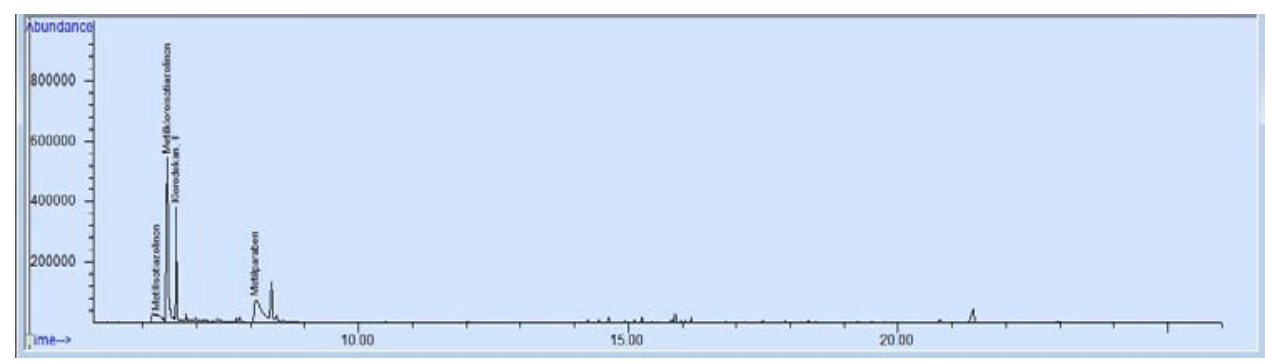

Fig. 8: Chromatogram of the rinse-off spiked sample

Table 5: Matrix effect and linearity parameter in solvent extraction and cosmetic matrices

\begin{tabular}{|c|c|c|c|c|c|c|c|c|}
\hline \multirow[t]{2}{*}{ Analyte } & \multicolumn{2}{|c|}{ Solvent calibration } & \multicolumn{3}{|c|}{ Matrix calibration leave-on } & \multicolumn{3}{|c|}{ Matrix calibration rinse-off } \\
\hline & $\mathbf{r}$ & Vxo (\%) & $\mathbf{r}$ & Vxo & Matrix effect (\%) & $\mathbf{r}$ & Vxo & Matrix effect (\%) \\
\hline MI & 0.9987 & 4.75 & 0.9967 & 0.026 & 583.20 & 0.9989 & 0.0148 & 632.61 \\
\hline MCI & 0.9999 & 4.12 & 0.9985 & 0.018 & 253.68 & 0.9991 & 0.0133 & 321.35 \\
\hline
\end{tabular}

MI = Methylisothiazolinone; $\mathrm{MCI}=$ Methylchloroisothiazolinone

\section{Matrix effect (ME)}

Matrix effect (ME) results are shown in table 5 . As can be seen, ME for $\mathrm{MI}$ in leave-on and rinse-off samples showed signal enhancement (583.20\% and $632.61 \%$, respectively). For MCI, ME was also considered as signal enhancement in both matrices. ME value for the leave-on sample was $253.68 \%$ and for the rinse-off sample was $321.35 \%$.

Signal enhancement or matrix-induced enhanced chromatographic effect in GC-MS could be caused by the presence of sample matrix components in the GC injector and column. Furthermore, silanol active sites in those chromatographic systems can be masked by adsorption of nonvolatile matrix components, lead to an increased transfer of target analytes into the detector, and effectively enhance analytes signals compared to matrix-free injection. This effect was observed probably due to the co-extraction of nonvolatile components by ethyl acetate [16].

To correct this effect, the analytes were quantified using a curve in the matrix calibration (MC). Matrix calibration is calibration standards usually made up by adding calibration standards including internal standards to a blank matrix and are subjected to sample preparation and analysis [17]. Matrix calibration used in this analysis was calibration from linearity study. This is because MC will account for analyte losses during sample preparation and matrix effects during analysis.

\section{Accuracy}

Method accuracy is executed by adding standards solution at a range concentration of $80 \%, 100 \%$, and $120 \%$ (three replicates per concentration) to the sample (spiked placebo recovery method) and then the analytical signals obtained for each spiked samples were quantified using the calibration curve of standard solutions that were prepared with matrix blank sample (matrix calibration).

The recovery value of MI for the rinse-off product was 99.84$103.15 \%$ and for the leave-on product was $100.00-102.76 \%$. Meanwhile, the recovery value of MCI for the rinse-off product was $97.65 \%-100.72 \%$ and for the leave-on product was $97.87-100.54 \%$ (table 6). These findings are quite similar with those found in the literature for MI and MCI assay in cosmetic products employing UHPLC-MS/MS [18].

Table 6: Accuracy of MI and MCI

\begin{tabular}{|c|c|c|c|c|c|c|}
\hline \multirow[t]{3}{*}{ Exposure type } & \multicolumn{6}{|c|}{ Recovery (\%) (n=3) } \\
\hline & \multicolumn{2}{|l|}{$80 \%$} & \multicolumn{2}{|l|}{$100 \%$} & \multicolumn{2}{|l|}{$120 \%$} \\
\hline & MI & MCI & MI & MCI & MI & MCI \\
\hline Leave-on & 100.00 & 100.54 & 100.97 & 97.87 & 102.76 & 98.87 \\
\hline Rinse-off & 103.15 & 97.65 & 100.62 & 100.44 & 99,84 & 101.46 \\
\hline
\end{tabular}

\section{Precision}

Method precision was investigated in spiked samples containing three concentration levels and each concentration was injected three times. Relative standard deviation (RSD) values for both intraday (repeatability) and interday (intermediate precision) were determined by sequentially injecting spiked samples either within a single day (intraday) or over two days (interday). RSD values were calculated using matrix calibration to compensate for the matrix effect and the value for both analyte in leave-on and rinse-off product were, in general, below $7 \%$, reaching values lower than $11 \%$, which is met the acceptance criteria for precision (table 7 and table 8). 
Table 7: Precision of MI and MCI for leave-on sample

\begin{tabular}{|c|c|c|c|c|c|c|}
\hline \multirow[t]{2}{*}{ Parameter } & \multicolumn{3}{|l|}{ MI } & \multicolumn{3}{|l|}{ MCI } \\
\hline & $\begin{array}{l}\text { Conc. } \\
(\mu \mathrm{g} / \mathrm{ml})\end{array}$ & $\begin{array}{l}\text { Mean Calc. Conc. } \\
(\mu \mathrm{g} / \mathrm{ml})\end{array}$ & RSD (\%) & $\begin{array}{l}\text { Conc. } \\
(\mu \mathrm{g} / \mathrm{ml})\end{array}$ & $\begin{array}{l}\text { Mean Calc. Conc } \\
(\mu \mathrm{g} / \mathrm{ml})\end{array}$ & RSD (\%) \\
\hline \multirow[t]{3}{*}{ Repeatability } & 3 & 2.998 & 0.508 & 9 & 9.0583 & 1.064 \\
\hline & 3.75 & 3.784 & 1.989 & 11.25 & 11.023 & 2.255 \\
\hline & 4.5 & 4.621 & 1.334 & 13.5 & 13.362 & 0.280 \\
\hline \multicolumn{7}{|c|}{ Intermediate Precision } \\
\hline \multirow[t]{3}{*}{ Day 2} & 3 & 3.097 & 8.619 & 9 & 8.317 & 0.718 \\
\hline & 3.75 & 3.518 & 4.077 & 11.25 & 9.667 & 4.091 \\
\hline & 4.5 & 4.661 & 3.644 & 13.5 & 11.531 & 3.138 \\
\hline \multirow[t]{3}{*}{ Day 3} & 3 & 2.900 & 2.557 & 9 & 8.530 & 1.437 \\
\hline & 3.75 & 3.456 & 4.236 & 11.25 & 10.280 & 1.750 \\
\hline & 4.5 & 4.805 & 7.354 & 13.5 & 11.418 & 1.505 \\
\hline
\end{tabular}

Conc: Concentration, Mean Calc. Conc: Mean Calculated Concentration

Table 8: Precision of MI and MCI for rinse-off product

\begin{tabular}{|c|c|c|c|c|c|c|}
\hline \multirow[t]{2}{*}{ Parameter } & \multicolumn{3}{|l|}{ MI } & \multicolumn{3}{|l|}{ MCI } \\
\hline & $\begin{array}{l}\text { Conc. } \\
(\mu \mathrm{g} / \mathrm{ml})\end{array}$ & $\begin{array}{l}\text { Mean Calc. Conc. } \\
(\mu \mathrm{g} / \mathrm{ml})\end{array}$ & RSD (\%) & $\begin{array}{l}\text { Conc } \\
(\mu \mathrm{g} / \mathrm{ml})\end{array}$ & $\begin{array}{l}\text { Mean Calc. Conc } \\
(\mu \mathrm{g} / \mathrm{ml})\end{array}$ & RSD (\%) \\
\hline \multirow[t]{3}{*}{ Repeatability } & 3 & 3.092 & 1.405 & 9 & 8.822 & 0.691 \\
\hline & 3.75 & 3.771 & 0.726 & 11.25 & 11.343 & 0.146 \\
\hline & 4.5 & 4.441 & 1.469 & 13.5 & 13.743 & 0.457 \\
\hline \multicolumn{7}{|c|}{ Intermediate Precision } \\
\hline \multirow[t]{3}{*}{ Day 2} & 3 & 3.369 & 3.030 & 9 & 9.485 & 2.848 \\
\hline & 3.75 & 4.443 & 1.718 & 11.25 & 12.123 & 1.530 \\
\hline & 4.5 & 4.657 & 8.045 & 13.5 & 14.404 & 4.722 \\
\hline \multirow[t]{2}{*}{ Day 3} & 3 & 3.218 & 5.786 & 9 & 8.275 & 4.005 \\
\hline & 3.75 & 3.174 & 7.050 & 11.25 & 11.742 & 6.438 \\
\hline
\end{tabular}

Conc: Concentration, Mean Calc. Conc: Mean Calculated Concentration

\section{Limit of detection (LOD) and limits of quantitation (LOQ)}

Limit of detection and limit of quantitation were determined using the regression equation approach and calculated statistically through the line of linear regression from the spiked sample calibration curve. MI and MCI's LOD and LOQ values for both leave-on and rinse-off samples are shown in table 9. LOD and LOQ values were both below the maximum permitted concentration established by Indonesian FDA legislation in cosmetics.

\section{Analysis of samples}

Cosmetic samples purchased on the market were evaluated by validated GC-MS methods. Data of MI and MCI concentration in each sample were presented in table 10 .

Table 9: LOD and LOQ values

\begin{tabular}{llll}
\hline Parameter & MI & MCI & \\
\cline { 2 - 4 } & Leave-on & Rinse-off & Leave-on \\
\hline LOD $(\mu \mathrm{g} / \mathrm{ml})$ & 0.289 & 0.167 & 0.586 \\
LOQ $(\mu \mathrm{g} / \mathrm{ml})$ & 0.964 & 0.556 & 1.953 \\
\hline
\end{tabular}

Table 10: Determination MI and MCI with GC-MS method

\begin{tabular}{|c|c|c|c|c|c|}
\hline Sample & Exposure type & Ingredient list & MI (\%) & MCI (\%) & Calculated MCI/MI ratio \\
\hline Face cream & Leave-on & MI & 0.00034 & - & - \\
\hline Sunscreen & Leave-on & MI & NQ & - & - \\
\hline Wet tissue 1 & Leave-on & MI & 0.01370 & - & - \\
\hline Baby shampoo 1 & Rinse-off & MI & 0.00368 & - & - \\
\hline Baby shampoo 2 & Rinse-off & MI & 0.00916 & - & - \\
\hline Body wash & Rinse-off & MI & 0.00102 & - & - \\
\hline Body Lotion & Leave-on & MI and MCI & NQ & 0.00077 & - \\
\hline Wet tissue 2 & Leave-on & MI and MCI & 0.00072 & NQ & - \\
\hline Wet tissue 3 & Leave-on & MI and MCI & 0.00012 & NQ & - \\
\hline Child shampoo & Rinse-off & MI and MCI & 0.00074 & 0.00240 & 3.24 \\
\hline Shampoo 1 & Rinse-off & MI and MCI & 0.00402 & NQ & - \\
\hline Shampoo 2 & Rinse-off & MI and MCI & 0.00073 & NQ & - \\
\hline Shampoo 3 & Rinse-off & MI and MCI & 0.00307 & NQ & - \\
\hline Conditioner 1 & Rinse-off & MI and MCI & 0.00084 & NQ & - \\
\hline Conditioner 2 & Rinse-off & MI and MCI & 0.00074 & 0.00263 & 3.55 \\
\hline Conditioner 3 & Rinse-off & MI and MCI & 0.00077 & NQ & - \\
\hline Face Cleanser 1 & Rinse-off & MI and MCI & 0.00080 & NQ & - \\
\hline Face Cleanser 2 & Rinse-off & MI and MCI & 0.00073 & NQ & - \\
\hline
\end{tabular}

NQ: Not Quantitated 
Eighteen cosmetic products were purchased from the market consist of 13 rinse-off products and 5 leave-on products. The products were either contained MI alone or a combination of MCI/MI. In products contained MI alone, the proposed method could detect most of the samples, except for sample sunscreen. There was a leave-on product that still contained MI and MI concentration in most of the rinse-off products were exceed the permitted limit of maximum concentration. This is due to the effective date of the new regulation, which stated that the permitted limit of MI alone in rinse-off products is $0.0015 \%$ and was prohibited in leave-on products was 22 August 2020, and the samples were purchased before that.

MI was listed as an ingredient in all 18 purchased products and the GCMS method was able to detect $89 \%$ (16 products). MCI was listed as an ingredient in 12 surveyed products, but the method could only detect $25 \%$ (3 products). Nevertheless, the GC-MS method could analyze products that contain MI and MCI in a calculated ratio similar to that of Kathon $^{\mathrm{TM}}$ CG (3:1). MCI could not be detected in most of the purchased products, probably due to the reaction of MCI and/or MI with other cosmetic ingredients within a given product. The previous study also observed that the MCI degradation in shampoo formulations was occurred due to an additional electrophilic center in the MCI molecule, which made it more unstable than MI and was prone to interact with other ingredients in shampoo matrices [19]. Hence, this method would be appropriate to observe the incorrect labeling of MI and MCI on cosmetic product ingredient lists. The limitation of this method is that the matrix effect was significant, so it can impact the quantification process of analytes. Moreover, this method also could not detect MCI optimally. Despite all of the limitations, this validated method could be applied for routine analysis. For future studies, the vortexassisted MSPD might be used as an extraction technique with some modifications to produce a higher extraction yield and to minimize the matrix effect.

\section{CONCLUSION}

An MSPD-GC-MS method has been proposed for the determination MI and $\mathrm{MCI}$ that are being subjected to the Indonesian FDA regulation amendment. The optimum conditions for the MSPD procedure were using alumina as solid sorbent and ethyl acetate as eluent. Original MSPD was chosen instead of vortex-assisted MSPD (VA-MSPD), but VA-MSPD has a great potency to be further developed in order to be an alternative extraction technique. Local sorbent from Indonesia has also been assessed in this study and the results appeared that local quartz sand from Rembang, Indonesia is a potential sorbent for extraction method. MI and MCI can be separated by gas chromatography-mass spectrometry (GC-MS) using DB-5MS column (length $30 \mathrm{~m}$, internal diameter $0.25 \mathrm{~mm}$, film thickness $0.25 \mu \mathrm{m}$ ) and the optimum GC-MS analysis conditions were as follows: injector temperature was $250{ }^{\circ} \mathrm{C}$, detector temperature at $250{ }^{\circ} \mathrm{C}$, the oven temperature was programmed to increase from $60^{\circ} \mathrm{C} / \mathrm{min}$ (held for 2 $\min$ ) to $175^{\circ} \mathrm{C}$ (held for $7 \mathrm{~min}$ ) at $25^{\circ} \mathrm{C} / \mathrm{min}$ and then increase to 295 ${ }^{\circ} \mathrm{C}$ (held for $10 \mathrm{~min}$ ) at $50{ }^{\circ} \mathrm{C} / \mathrm{min}$, the helium flow rate was 1.2 $\mathrm{ml} / \mathrm{min}$. The method has passed validation acceptance criteria and could be applied in purchased cosmetic samples.

\section{ACKNOWLEDGEMENT}

The authors are grateful to the Indonesian Food and Drug Authority (Indonesian FDA) for the research cost

\section{FUNDING}

Indonesian Food and Drug Authority.

\section{AUTHORS CONTRIBUTIONS}

All of the authors have contributed equally.

\section{CONFLICT OF INTERESTS}

The authors declare that they have no conflicts of interest.

\section{REFERENCES}

1. Alvarez Rivera G, Llompart $M$, Lores M, Garcia Jares C. Preservatives in cosmetics: regulatory aspects and analytical methods. In: Salvador A, Chisvert A. editors. Analysis of cosmetic products. $2^{\text {nd }}$ ed. Oxford: Elsevier BV; 2018.

2. Magdaleno Tapial J, Valenzuela Onate C, Ortiz Salvador JM, Garcia Legaz Martinez M, Martinez Domenech A, Alonso Carpio $\mathrm{M}$, et al. Contact allergy to isothiazolinones epidemic: current situation. Contact Dermatitis 2019;1-4.

3. Badan Pengawas Obat dan Makanan Republik Indonesia. Peraturan badan pengawas obat dan makanan republik Indonesia nomor 23 tahun 2019 tentang persyaratan teknis bahan kosmetika. Jakarta: Badan Pengawas Obat dan Makanan Republik Indonesia; 2019.

4. Ilankizhai RJ, Gayathri R, Vishnupriya V. Cosmetic contamination awareness among adolescent females. Asian J Pharm Clin Res 2016;9:117-20.

5. Balakrishnan J, Appalasamy JR. Skin infection and the global challenges: a review. Int J Pharm Pharm Sci 2016;8:1-3.

6. Balakrishnan J, Appalasamy JR, Verma RK. A study on awareness of skin infection among adults in Petaling district, Malaysia. Int J Pharm Pharm Sci 2016;8:136-9.

7. Silva V, Silva C, Soares P, Garrido EM, Borges F, Garrido J. Isothiazolinone biocides: chemistry, biological, and toxicity profiles. Molecules 2020;25:1-22.

8. Rafoth A, Gabriel S, Sacher F, Brauch HJ. Analysis of isothiazolinones in environmental waters by gas chromatography-mass spectrometry. J Chromatogr A 2007;1164:74-81.

9. Gopalan SV, Hasanah AN. MI-SPE, M-SPE and M-SPD recent application on solid-phase extraction for compound extraction of complex matrices. Int J Appl Pharm 2019;11:16-25.

10. Alvarez Rivera G, Dagnac T, Lores M, Garcia Jares C, Sanchez Prado L, Lamas JP, et al. Determination of isothiazolinone preservatives in cosmetics and household products by matrix solid-phase dispersion followed by high-performance liquid chromatography-tandem mass spectrometry. J Chromatogr A 2012;1270:41-50.

11. Park SK, Kwon JH. The fate of two isothiazolinone biocides, 5chloro-2-methylisothiazol-3(2H)-one (CMI) and 2methylisothiazol-3(2H)-one (MI), in liquid air fresheners and assessment of inhalation exposure. Chemosphere 2016;144:2270-6.

12. dos Santos EO, Gonzales JO, Ores JC, Marube LC, Caldas SS, Furlong EB, et al. Sand as a solid support in ultrasound-assisted MSPD: a simple, green and low-cost method for multi-residue pesticide determination in fruits and vegetables. Food Chem 2019;297:1-12.

13. International Conference on Harmonization (ICH). Validation of analytical procedures: text and methodology Q2 (R1). Geneva: International Conference on Harmonization; 2005.

14. Harmita. Analisis fisikokimia: Kromatografi. Vol. 2. Jakarta: Penerbit Buku Kedokteran EGC; 2015.

15. Dettmer Wilde K, Engewald W. Quantitative analysis. In: Dettmer Wilde K, Engewald W. editors. Practical gas chromatography. First. Berlin: Springer-Verlag; 2014. p. 271302.

16. Caban M, Migowska N, Stepnowski P, Kwiatkowski M, Kumirska J. Matrix effects and recovery calculations in analyses of pharmaceuticals based on the determination of $\beta$-blockers and $\beta$-agonists in environmental samples. J Chromatogr A 2012;1258:117-27.

17. FAO-WHO. Codex alimentarius: Guidelines on performance criteria for methods of analysis for the determination of pesticide residues in food and feed. rome: food and agriculture organization of the united nations; 2017.

18. Wittenberg JB, Canas BJ, Zhou W, Wang PG, Rua D, Krynitsky AJ. Determination of methylisothiazolinone and methylchloroisothiazolinone in cosmetic products by ultra high-performance liquid chromatography with tandem mass spectrometry. J Sep Sci 2015;38:2983-8.

19. Tomas M, Agonia AS, Borges L, de Oliveira AP, de Oliveira RP. Isothiazolinones quantification in shampoo matrices: a matter of method optimization or stability driven by interactions? Cosmetics 2020;7:1-13. 